Portland State University

PDXScholar

Political Science Faculty Publications and

Presentations

3-1-2005

\title{
The Black Market in Small Arms: Examining a Social Network
}

David Todd Kinsella

Portland State University

Follow this and additional works at: https://pdxscholar.library.pdx.edu/polisci_fac

Part of the International Relations Commons, and the Models and Methods Commons Let us know how access to this document benefits you.

Citation Details

Kinsella, David Todd, "The Black Market in Small Arms: Examining a Social Network" (2005). Political Science Faculty Publications and Presentations. 4.

https://pdxscholar.library.pdx.edu/polisci_fac/4

This Conference Proceeding is brought to you for free and open access. It has been accepted for inclusion in Political Science Faculty Publications and Presentations by an authorized administrator of PDXScholar. Please contact us if we can make this document more accessible: pdxscholar@pdx.edu. 


\title{
THE BLACK MARKET IN SMALl ARMS: EXAMINING A SOCIAL NETWORK
}

\section{David Kinsella}

\author{
Hatfield School of Government \\ Portland State University \\ kinsella@pdx.edu
}

\begin{abstract}
$\underline{\text { Abstract }}$
In recent years, researchers have increasingly turned their attention to the proliferation of small arms, a transnational trade amounting to over $\$ 7$ billion in value during 2002. Small arms are difficult to track and are not the stuff of military parades, but they are immensely destructive. As much as $\$ 1$ billion worth enters the black market annually. I argue that the illicit trade in small arms should be understood not as a market but as a network, one that shares some important properties with networked forms of organization studied by sociologists. I then employ quantitative methods developed for the study of social networks in an effort to show the basic structure of illegal small arms transfers to Africa. The analysis draws from my Illicit Arms Transfers (IAT) dataset still in its early stages of development, so the results are preliminary. They are suggestive, however, and the analytical approach promises to shed considerable light on a corner of the global arms trade that is of great interest to the research and activist communities, and of great consequence to those in war-torn regions of the world.
\end{abstract}

Paper prepared for presentation at the annual meeting of the International Studies Association, March 2005, Honolulu. My thanks to Nicholas Marsh for supplying the reports contained in NISAT’s Black Market Archives. 


\section{THE BLACK MARKET IN SMALL ARMS: EXAMINING A SOCIAL NETWORK}

An estimate of the global value of small arms production in 2002 is $\$ 7.4$ billion. Well over 1,000 companies manufacture light weapons and ammunition in nearly 100 countries. More than half of what is manufactured, $\$ 4$ billion worth, is transferred legally across national borders, while as much as $\$ 1$ billion worth enters the international black market (Small Arms Survey 2003; Marsh 2002). Credible estimates have only become available in recent years as arms trade researchers, international organizations, and activists have increasingly turned their attention to what was once merely a footnote in scholarship and policymaking on matters of proliferation and arms control. Far more people are killed by rifles, pistols, grenades, and landmines (not to mention machetes) than attack aircraft, main battle tanks, and missiles. Small arms are, in a very real sense, weapons of mass destruction.

Most small arms transfers are economic exchanges, but they are often exchanges governed by more than market forces. As such, they are the type of transactions of interest to sociologists dissatisfied with the neoclassical economic approach in organizational theory, which is judged as excessively utilitarian and insufficiently attentive to the impact of social relations on economic behavior. Nor are arms transfers governed by hierarchical authority, as are exchanges within vertically integrated firms or conglomerates, the emergence of which are often explained as a response to market transaction costs.

In between the hierarchy of the firms and the anarchy of the market are network forms of organization and exchange. They depend not on formal authority, but on shared interests and ongoing relationships. Whereas market transactions are undertaken to maximize returns in the short and medium term, network exchanges are sequential and contribute to an overall pattern of 
enduring interaction. Because the mechanism of governance rests largely on trust and obligation, network forms of organization function well when composed of homogenous groups of actors. The opportunism and guile contributing to high transaction costs in the impersonal market setting is less common among those sharing professional, ethnic, or ideological backgrounds, and thus hierarchical governance structures are less likely to emerge.

The small arms trade is characterized by some of the same features found in network forms of economic organization. Decisions to supply and purchase weaponry are often elements in ongoing arms-transfer arrangements, which are sometimes part of more general military relationships. This holds whether the actors in question are states or nonstate entities, like rebel groups or paramilitary organizations. While particular arms-transfer agreements may ostensibly take the form of arms-length contracts, much of their meaning is lost if they are extracted from this "social context." Instead of contracts, they may actually resemble longer-term investments in mutually beneficial relationships. Of course, not all small arms transfers-legal or illegal, between states or nonstate actors - are of this sort, so thick with meaning. Many do resemble market transactions in which little more is involved than the sale of military hardware by one party to another.

This paper is a preliminary examination of the illegal trade in small arms, conceptualized as a social network. It is preliminary in two ways. First, I am in the fairly early stages of collecting data on illicit arms transfers, an effort that involves coding information contained in news accounts from various sources, and here I conduct an analysis of a subset of events for which the data are reasonably complete for present purposes: arms shipments to, from, and within Africa. Second, the method of analysis used in this paper, social network analysis (SNA), 
consists of a number of both descriptive and inferential techniques. The techniques most appropriate for mapping the small arms trade are the descriptive ones, but it is also the case that any mapping using descriptive methods is likely to be sensitive to missing and noisy data. Nevertheless, having entered these caveats, I want to give some sense of the main locales involved in Africa's illegal small arms trade, as well as the usefulness of network analytical methods for illuminating the structural features of this particular black market. Before moving on to the empirical analysis, however, I expand on my rationale for treating the small arms trade as a social network.

\section{THE ARMS NETWORK}

A market is a social entity that governs transactions between producers and consumers by way of a price mechanism, and economists typically locate pure markets at one end of a range of possible arrangements for the exchange of goods and services. This is the anarchic end. No authority is exercised in a pure market; economic production is governed by prices, which result from individual decisions affecting supply and demand. At the hierarchical end are organized social entities like firms. Within a firm, economic production is governed by an entrepreneur, whether an individual or a collective, who directs the allocation of resources within the organization. One of the questions that has occupied economists is: under what circumstances do markets give rise to hierarchical organizations as a means of coordinating economic exchange?

The classic treatment of this issue is by Coase $(1937,392)$, who maintained that "the operation of a market costs something and that, by forming an organization and allowing some authority (the 'entrepreneur') to direct the resources, certain marketing costs are saved" (see also 
Lindblom 1977, chap. 3). In contemporary scholarship, these sorts of costs are termed "transaction costs," and they generally derive from the inefficiencies associated with incomplete information (e.g., Williamson 1981). Some economic transactions involve uncertainties-e.g., about continued access to specialized inputs into the production process - and although these might be handled by entering into contracts, the continual negotiation and renegotiation of contracts is costly. Such transaction costs, at least some of them, can be eliminated if the parties enter into an exchange relationship governed according to the bylaws of a hierarchical organization. Under these circumstances, firms will realize efficiencies not available in the open market and economic production and exchange will become more profitable.

Patterns of economic exchange governed by more than market forces but by less than hierarchical organizations have been of considerable interest to sociologists. Granovetter (1985), for instance, has echoed the common criticism of the neoclassical economic approach to organization as offering a utilitarian and "undersocialized" conception of human action in which little allowance is made for the impact of social relations on economic exchange (except as a drag on the efficient allocation of resources). At the same time, early sociological correctives tended to propose "oversocialized" conceptions of behavior whereby individuals simply, and somewhat robotically, internalize societal norms, also leaving little room for the impact of ongoing social relations (see also Wrong 1961). For Granovetter and others, economic behavior is governed not only by institutional arrangements designed to discourage malfeasance and reduce transaction costs, or by a "generalized morality" instilled through the socialization process, but also by trust. Economic action is embedded in ongoing social interaction and more emphasis needs to be placed on "the role of concrete personal relations and structures (or 
'networks') of such relations in generating trust and discouraging malfeasance" (Granovetter $1985,490)$.

A similar gap seems to exist in the political science literature on international organization. Liberals have criticized realists for failing to see international institutions as more than epiphenomena deriving from the distribution of state power. Instead, taking cues from new institutional economics, liberals see them as "information-providing and transaction costreducing entities" (Keohane 1984, 101). Constructivists, in turn, taking cues from the institutionalist approach in sociology, fault liberals (and realists) for neglecting "the production and reproduction of identities and interests" and for assuming that "how states treat each other in interaction does not matter for how they define who they are" (Wendt 1999, 36; see also Finnemore 1996). ${ }^{1}$ But to date the focus of constructivist analysis has been on the socialization of states — "states are people too," Wendt $(1999,215)$ says — and on the emergence and reinforcement of norms in international society, rather than on relations between states and outcomes that fall short of norm creation and institution building. ${ }^{2}$

In departing from transaction-cost explanations, sociologists who study economic organization are not abandoning the notion of rational action. They are suggesting that social constraints, or "embeddedness," often makes seemingly nonrational behavior appear quite reasonable. Many economic transactions "aim not only at economic goals but also at sociability,

${ }^{1}$ This argument between realists, liberals, and constructivists fills many pages in the international relations literature. For a shortcut through the debate, see Mearsheimer (1994/95) and the follow-on symposium on institutions in the summer 1995 issue of International Security.

${ }^{2}$ The individualist orientation of the realist and liberal traditions in international relations theory probably guards against any tendency that constructivists might have to adopt an oversocialized conception of state action. Constructivists' preoccupation with norms, institutions, and identity formation, instead of interstate relationships, is perhaps temporary-due less to the ontology of constructivism than to its newness to the field. 
approval, status, and power" (Granovetter 1985, 506). In the realm of world politics, those studying the arms production and transfer system have frequently observed that the arms acquisition policies of both developed and developing states don't always make sense in terms of either military or economic efficiency. The "rationality" of those procurement patterns becomes apparent only when taking into account less material motives like status, prestige, and the symbols of modern statehood (e.g., Kaldor 1981; Suchman and Eyre 1992; Eyre and Suchman 1996; Wendt and Barnett 1993; Kinsella and Chima 2001). And no less an authority than Hans Morgenthau (1985, 86-87), realism's chief exponent, believed that “prestige, however exaggerated and absurd its uses may have been at times, is as intrinsic an element of the relations between nations as the desire for prestige is of the relations between individuals."

Inquiry into the role of social relations in the emergence of various forms of economic organization is of fairly recent origin in sociology. But much of the research that has been done on interpersonal relations in economic life focuses on the creation and maintenance of social networks. Less anarchic than markets, networks of economic actors are at the same time not hierarchically organized. Where price serves as a control mechanism in markets and authority serves that function within a vertically integrated firm, personal relationships, typically characterized by trust and a norm of reciprocity, are the glue that binds a social network together. It may well be that, under conditions conducive to social networks, hierarchically organized social entities are not required as a means of reducing uncertainty and managing transaction costs, but from a sociological point of view that begs some important questions. What are those conditions? To what extent can they be explained by the social, cultural, and political practices 
that embed economic interaction? Alternatively, to what extent can they be explained by the nature of particular forms of economic exchange?

Powell (1990) addresses the last of these questions, maintaining that some forms of exchange are inherently more social than others. They depend not so much on formal authority, but on shared interests and ongoing relationships. In network forms of exchange, "the entangling of obligation and reputation reaches a point that the actions of the parties are interdependent." The pattern of interaction "looks more like a marriage than a one-night stand, but there is no marriage license, no common household, no pooling of assets" (Powell 1990, 301). Whereas market transactions are undertaken to maximize returns in the short and medium term, network exchanges are sequential and contribute to an overall pattern of enduring interaction. Much of what is exchanged in social networks is difficult to price-know-how and styles of production, for example — so the flow of information through networks is often "richer" than what is transmitted by the price mechanism in markets or by controlled channels of communication within a vertically integrated firm. Finally, because the mechanism of governance rests largely on trust and obligation, network forms of organization function well when composed of homogenous groups of actors. The opportunism and guile contributing to high transaction costs in the impersonal market setting is less common among those sharing professional, ethnic, or ideological backgrounds, and thus hierarchical governance structures are less likely to emerge.

\section{State-sanctioned Arms Transfers}

The arms trade is characterized by some of the same features found is network forms of economic organization. Decisions to supply and purchase weaponry are often elements in 
ongoing arms-transfer relationships. In the case of state-sanctioned transfers, they are elements of more general military relationships. The supply of finished weapons systems can be accompanied by instruction in the operation and maintenance of equipment, construction of support facilities, and other forms of technical assistance. Arms transfers are, in many instances, embedded in relationships of mutual defense - e.g., weapons flows between members of formal military alliances like NATO — or in less formal commitments by suppliers to the security of recipient states. Those more general military relations, whether formal or implied, may also involve basing and overflight rights, military training and joint exercises, the coordination of strategy and tactics, the sharing of military intelligence, and other forms of collaboration intended to enhance the security of both parties to the transaction. While particular arms-transfer agreements may take the form of arms-length contracts, much of their meaning is lost if they are extracted from this "social context." Instead of contracts, they may actually resemble long-term investments in mutually beneficial interstate relationships.

Consistent with Powell's (1990) description of exchanges within networks, it is difficult to attach a value to the political and military commitments that often accompany arms transfers between states. In addition to interstate commitments, weapons supplies embody the transfer of military technology, and many deals include arrangements for the licensed production of military equipment by the recipient. This flow of technology and know-how between states, which is also hard to price, is an important feature of the contemporary arms trade and has had a measurable impact on the emergence of a "third tier" of arms producers in the international system (Krause 1992; Bitzinger 1994; Kinsella 2000). Thus, the information and meaning embodied in arms 
transfers can be substantially richer than what might be indicated by the market or military-use value of the weapons themselves.

Much more is involved in these transactions than a shipment of some increment of destructive capability from one to another state. Because arms transfers are indicative of the supplier's commitment to the recipient's security, as well as the recipient's expectation (perhaps backed up with certain concessions) that it can count on this commitment into the future, the most significant and enduring arms-transfer relationships link states with congruent foreign policy orientations. During the cold war, for instance, the United States and its allies tended to supply arms to states whose policies were generally in accord with the global political-economic status quo, while the Soviet Union and its allies tended to supply dissatisfied or revisionist states (Kinsella 1994). There was, then, in the arms-transfer network a certain homogeneity among states with the closest and most dependable ties. Such shared foreign policy orientations are not unlike the shared backgrounds (professional, ethnic, religious) that help sustain social networks comprised of individuals.

\section{Black Market Transfers}

Of course, not all arms transfers between states are of this sort, so thick with meaning. Many do resemble market transactions in which little more is involved than the sale of military hardware by one party to another. Indeed, illicit arms transfers by private dealers are typically undertaken solely for reasons of economic gain, so it might seem that the market conceptualization ought to work well in this realm of the global arms trade. Yet illegal weaponry clearly does flow through 
transnational networks, as do narcotics and other contraband; on its face, "networkness" seems to be a more obvious feature of the black market arms trade than does its "marketness."

When comparing market and network forms of organization — and one could imagine hybrid forms as well (Bradach and Eccles 1989)—it is probably useful to distinguish between the nature of the goods being exchanged and the mode of exchange. Above I suggested that states sometimes transfer arms, or sanction the transfer of arms, for reasons other than economic gain; arms transfers embody security commitments as well as raw military capability. Analogous commitments usually do not attach to black market transfers, at least those involving private dealers and their brokers. But other types of commitments are involved that lend these transactions to network forms of organization. Specifically, because these arms transfers are illegal and must be kept out of view, the transactions that enable them-deal-making, document forgery, financial transfers, illicit transport, and so on—also must be kept out of view, and parties to the transaction must trust each other in this regard. Furthermore, in many cases, the parties to such transactions anticipate the need for future exchanges, and therefore would like to be able to return to, or reactivate, these transfer channels as those needs arise. Their options are kept open by a set of mutual understandings and commitments to the maintenance of the social network. $^{3}$

I am suggesting that, in the black market, transferred weaponry is not itself indicative of shared interests - say, common political or ideological goals that are furthered by the recipient's enhanced military capability. Yet the parties' separate interests - economic, military, or

${ }^{3}$ Duffield (2000) examines the key features of transborder trade, including the illicit arms trade, in the context of civil war (see also Kaldor 2001, chap. 5; Cooper 2002). Insightful discussions of black market arms transfers also include Klare (1997), Marsh (2002), Wood and Peleman (1999), and the essays in Lumpe (2000). 
otherwise - surely are served by the maintenance of the black market's infrastructure. Political, ideological, or other religious and ethnic attachments, may be relevant in a different way, however. Because black market arms transfers occur in a lawless environment, one without formal mechanisms of contract enforcement, parties to these transactions must rely more heavily on trust (often reinforced by threat) than is the case for legal market transactions. This is why many criminal organizations recruit members close to home. The social cohesion created by ethnic, religious, or ideological bonds reduces the likelihood of defection and thus the risks of operating in an extralegal environment. Economic theories of rebellion posit similar social dynamics (e.g., Collier 2000).

More theoretical work needs to be done in order to fully conceptualize the global arms trade, and its multiple legal and illegal forms, as a social network. Perhaps it is somewhat premature, then, to proceed with empirical analysis. Nevertheless, I believe that the network characteristics of the arms trade, and especially the black market trade, are sufficiently compelling that it is appropriate to simultaneously explore its structural features using some of the quantitative methods developed for social network analysis.

\section{SOCIAL NETWORK ANALYSIS}

The focus of social network analysis (SNA) is less on the attributes or behavior of actors than on the structural dimensions of their social environment, which are distilled from the overall pattern of relationships or exchanges among the actors. The social network itself is defined as the group of actors and the relationships or interactions that link them, and SNA methods are applied once it is assumed (or demonstrated) that a group of actors constitutes a network. That is, SNA is not a 
means of distinguishing networks from other forms of social organization, like anarchical or hierarchical forms, nor does it provide a way to assess the degree of "networkness" characterizing a given social grouping. The premise of SNA is that the organization of a set of interrelated actors bears some resemblance to a social network and that it is therefore useful to examine its structural dimensions. ${ }^{4}$

\section{The Illicit Arms Transfers Dataset}

The Illicit Arms Transfers (IAT) Dataset is an evolving datafile consisting of information gleaned from news reports of illegal arms shipments crossing interstate borders. The goal is to systematize the large amount of information that exists about the international black market in armaments (mostly small arms and light weapons) so that some of these data might be subjected to rigorous analysis, with special emphasis on the structures and vulnerabilities of the underground networks. The data collection effort involves scrutinizing written accounts of illegal arms shipments and extracting information according to established coding rules. Presently, the main source of raw data are the Black Market File Archives maintained by the Norwegian Initiative on Small Arms Transfers (NISAT 2004).

The unit of observation in the IAT Dataset is the arms transfer event - that is, a shipment of weapons from an originator to a recipient, possibly intercepted along the way. Each record in the database consists of data describing that event, including the actors and locations involved in the shipment's journey from originator to recipient (or interceptor), as well as the information

\footnotetext{
${ }^{4}$ The most authoritative and comprehensive guide to the methods of social network analysis is probably Wasserman and Faust (1994). For a briefer treatment, see Scott (2000). For a comprehensive review of the network analytical literature in multiple disciplines, see Newman (2003).
} 
source. Each variable is a descriptor and these event descriptors are grouped as they pertain to (a) the source of the arms shipment, (b) those involved in the arms deal, (c) the characteristics of the arms shipped, (d) the journey that the shipment took after leaving the source, and (e) the shipment's destination.

The reports in NISAT's archives vary widely in the amount of useful information contained therein. Some include detailed accounts of arms shipments from manufacturer to purchaser, and any number of participating intermediate dealers, brokers, and shipping agents. Other reports include no codable information at all. Some reports provide a wealth of background information, like previous events in an ongoing arms-supply relationship. Others pick up a particular shipment's journey midstream, as when one military organization supplies another organization, without any indication of where the first group acquired the weaponry. Even when reports contain relatively complete information, the events themselves exhibit a wide range of forms. There is substantial variation in the number and type of intermediaries engaged in the transfers, the nature of the illegalities involved (forges end-user certificates, arsenal theft, etc.), and whether the transfers were intercepted by state authorities or someone else other than the intended recipient.

The informational requirements for the present analysis are minimal, however. Networks consist of nodes and links (or, in the language of graph theory, "vertices" and "edges"). I examine the illegal arms network operating in Africa, and the nodes in this network are operationalized as the state locales from which, to which, or through which illicit weapons shipments have moved. Eventually, the IAT Dataset will allow me to operationalize network nodes as actors involved in these transactions, with locale simply being one of their attributes, 
but a more refined analysis must await further database development. State locales are nodes in the network examined here if they were involved in at least one illegal arms transfer during the 1990-2002 period, the time span for which I have coded data, and if there was sufficient information to identify the state locale at both ends of the transfer (even if the locale was only a transshipment point). No other information from the database is used here. The network consists of 74 nodes - 37 African states and 37 non-African states - with 209 links among them.

\section{Network Structure}

Barabási and his associates have observed the ubiquity of networks in physical, biological, and social systems, and they point out that many of these networks have "scale-free" structures (Barabási and Albert 1999; Barabási and Bonabeau 2003). In contrast to random networks, in which links or social ties are distributed randomly across the nodes, scale-free networks consist of some nodes with large numbers of connections (network hubs), and many others with very few connections. For example, Barabási and associates have found that links to pages on the World Wide Web have a "power law" distribution:

$$
P(k) \approx k^{-\gamma}
$$

where $P(k)$ is the probability of a network node with $k$ links; $k$ is the number of links per node; and the exponent $-\gamma$ is a constant. One implication is that scale-free networks are resilient to random failures of their nodes and links; the existence of well-connected hubs sustains the network's connectivity by providing paths between many pairs of nodes. On the other hand, targeted attacks on one or more hubs may bring about catastrophic network failure. 
Figure 1 depicts the illicit arms market operating in Africa, and it is clear that this is not a random network. Some state locales are much more connected in the black market arms trade than are others: Angola (AGO), South Africa (ZAF), Kenya (KEN), Democratic Republic of Congo (ZAR), Uganda (UGA), and Sudan (SDN), for example, but also some non-African participants like Ukraine (UKR), Romania (ROM), and Bulgaria (BGR). The latter are primarily supplier locales, of course, while the former are recipient locales and transshipment points.

[Figure 1 about here]

Figure 2 shows the distribution of $k$-linked state locales. The probability of being linked to $k$ other network nodes diminishes rapidly as $k$ increases, and this is true for the distribution of arms inflow and outflow locales. However, the power law model does provide a considerably closer fit to the distribution of outflow state locales, and the probability of being linked to other nodes declines more sharply compared to inflow locales $\left(\mathrm{R}^{2}=0.95, \gamma=1.23\right)$. If this pattern holds up with improved data, it will provide support for argument that the illicit arms trade can be disrupted more efficiently by targeting outflow hubs, which are somewhat more important to the network's connectivity.

[Figure 2 about here]

The estimated exponents for the distributions shown in Figure 2 are lower than those typically reported for scale-free networks like the World Wide Web, sexual partners, or communities of collaborating scholars, which the literature suggests ranges between 2.0 and 3.0. Barabási and Albert (1999) show that such networks emerge when there is a constant addition of new nodes over time (dynamic growth) and when these new nodes link to older nodes with higher probability than they link with newer nodes (preferential attachment). One possible 
explanation for the smaller exponents I am obtaining is that they are an artifact of having operationalized network nodes as state locales rather the actual actors involved in the transactions. The addition of state locales to the illicit arms network is limited by the number of independent states, whereas the addition of actors is not. Again, this possibility can be explored further as my database evolves.

\section{Central Locales}

An arms transfer is a directed link in that it represents the flow of military resources from one state locale (or actor) to another. The network data are arranged as a square "sociomatrix" in which there is both a row and a column for each node in the network. A cell in the matrix contains a 1 if an actor located in the state represented by row $i$, designated $n_{i}$, transferred arms to an actor in the state represented by column $j$, designated $n_{j}$, in which case $x_{i j}=1$; otherwise $x_{i j}$ $=0$. The main diagonal of the sociomatrix, where $i=j$, is ignored. ${ }^{5}$ The outdegree of node $i$, $d\left(n_{i}\right)$, is the number of other state locales to which arms from $n_{i}$ have been shipped; indegree, $d\left(n_{j}\right)$, is the total number of state locales from which arms to $n_{j}$ have been shipped. That is,

$$
d\left(n_{i}\right)=\sum_{\forall i \neq j} x_{i j} \text { and } d\left(n_{j}\right)=\sum_{\forall j \neq i} x_{j i}
$$

which are, respectively, the row $i$ and column $j$ totals of the sociomatrix. If there are $s$ state locales in the network, the maximum number of directed ties between them is $s\left(s^{-1}\right)$.

${ }^{5}$ There are SNA procedures that work with valued data-in the present context, for example, the total dollar equivalent of arms transferred between actors - but my analysis is based only on binary data indicating the presence or absence of an arms transfer sometime during the 1990-2002 period. Some more elaborate techniques, including some statistical estimators, make use of information about the attributes of actors as well as their links. See Wasserman and Faust (1994, chaps. 10 and 15). 
In most social networks, certain actors are more prominent than others and the evidence of their prominence is often the number and type of social ties they maintain with other actors. The centrality of a network actor is sometimes indexed as its outdegree or indegree (or both), but since these measures are greatly affected by the number of actors in a network, it is useful to normalize the index. Thus, the normalized outdegree and indegree centrality indexes for state locales in the illegal arms trade can be computed as

$$
C_{D}^{\prime}\left(n_{i}\right)=\frac{\sum_{\forall j \neq i} x_{i j}}{s-1} \text { and } C_{D}^{\prime}\left(n_{j}\right)=\frac{\sum_{\forall i \neq j} x_{j i}}{s-1} .
$$

Although this index will identify the most connected locales, it does so by counting only direct links between nodes. In the black arms market, where goods often reach their destinations through circuitous routes, central locales are also those that provide indirect conduits between suppliers and recipients. An alternative measure of centrality, closeness centrality, uses geodesic distances between nodes, which may be indirect paths with two or more legs. In a network comprised of directional links, like this one, the geodesic distance from node $i$ to node $j, d\left(n_{i}, n_{j}\right)$, is not necessarily the same as the distance from $j$ to $i, d\left(n_{j}, n_{i}\right)$. Central locales, defined in terms of closeness, are those that are connected to many others through short distance paths. Closeness centrality is computed as the inverse of the summed geodesic distances between node $i$ and all other nodes. A given node is maximally close to all others when it has direct links to all $\left(s^{-1}\right)$ of them, so the index can be normalized by using this distance in the numerator. That is,

$$
C_{C}^{\prime}\left(n_{i}\right)=\frac{s-1}{\sum_{\forall j \neq i} d\left(n_{i}, n_{j}\right)} \quad \text { and } \quad C_{C}^{\prime}\left(n_{j}\right)=\frac{s-1}{\sum_{\forall i \neq j} d\left(n_{j}, n_{i}\right)}
$$


Figures 3 and 4 arrange the state locales in the illicit arms trade so that the most central locales, in terms of closeness, are positioned nearer the center of ten concentric rings, while less central locales are positioned nearer the periphery. Figure 3 is constructed using inwardly directed geodesic distances ("in-closeness"). Angola, D.R. Congo, South Africa, and Sudan have the highest in-closeness scores, followed by Tanzania (TZA), Kenya, Zambia (ZMB), Liberia (LBR), the Republic of Congo (CON), Uganda, and Rwanda (RWA); they have the most direct and shortest indirect links to supplying locales. This is surely explained, in part, by high demand, as many have experienced sustained internal warfare during the period examined here. But related to this, perhaps as both cause and effect, is the existence of an underground infrastructure that makes getting weapons to these locales possible (even easy) — and of course profitable.

[Figure 3 about here]

The distribution of $k$-linked locales discussed above suggests that during the 1990-2002 period there were relatively fewer highly connected outflow states than inflow states, although the distribution of both types resembles the power law found to characterize scale-free networks. This can also be seen in Figure 4. Not surprisingly, the non-African countries, where primarily suppliers are located, are now positioned closer to the center of the chart, along with many African countries that function as both inflow and outflow locales. However, the arrangement is less concentrated than in Figure 3. Fewer states have closeness scores approximating South Africa's. The chart does effectively reveal the prominent role played by former Soviet bloc countries in Africa's illicit arms trade. Bulgaria, Ukraine, Romania, Russia (RUS), Slovakia (SVK), and the Czech Republic (CZK) are among the most highly connected outflow locales. 


\section{Pivotal Locales}

Nodes in a network may also be important to the extent that they are positioned between two other nodes. In the case of the illicit arms trade, when one locale, $n_{i}$, has links to two other locales, $n_{j}$ and $n_{k}$, which are not linked directly, $n_{i}$ may provide an important conduit for arms shipments between actors in $n_{j}$ and $n_{k}$. Some of the most important conduits are likely to be those lying on the geodesic paths connecting $n_{j}$ and $n_{k}$. Thus, another measure of centrality, betweenness centrality, starts with the number of geodesics, $g_{j k}$, linking nodes $j$ and $k$, and the number of these that contain node $i, g_{j k}\left(n_{i}\right)$. Betweenness can be measured as the sum of the probabilities that node $i$ will be pivotal in transactions between $j$ and $k:^{6}$

$$
C_{B}=\sum_{\forall j<k, j \neq i \neq k} \frac{g_{j k}\left(n_{i}\right)}{g_{j k}} .
$$

This measure is at its maximum when node $i$ is located on all geodesics in the network. Not including node $i$, there are $\left(s^{-1}\right)\left(s^{-2}\right)$ possible directional links, and half that number of possible nondirectional links. $C_{B}$ can therefore be normalized as:

$$
C_{B}^{\prime}=C_{B}\left(\frac{(s-1)(s-2)}{2}\right)^{-1}
$$

${ }^{6}$ This measure requires two crucial assumptions. First, an actor in $j$ who wants to reach an actor in $k$ is assumed to prefer the shortest path (or paths) linking the two locales. Second, when there are multiple geodesics linking $j$ and $k$, each has an equal probability of being chosen. Both assumptions are problematic if actors are expected to choose paths based not only on distance, but also on which locales (and actors) lie along the route. That, of course, is a reasonable expectation in the case of the black market arms trade. Nevertheless, I proceed in the hope that these assumptions might be relaxed in subsequent analyses. 
Figure 5 identifies the state locales with the highest betweenness centrality scores. All but Romania are African countries, and they are the same locales that rank highest according to the in-closeness measure. The literature on social and physical networks has long recognized the importance of such pivotal nodes in mediating the interactions between nonadjacent nodes (e.g., Shimbel 1953). Nodes characterized by high levels of betweenness are also the network's “high stress" points. Indeed, computing betweenness scores would seem to be the best way to identify the network's hubs and, for those wishing to disrupt the network, the best way to identify targets for concentrated attack.

[Figure 5 about here]

Closely related to this concept of betweenness is "brokerage." Brokers are nodes positioned between nonadjacent actors and through which a directional interaction takes place. Nodes that function as brokers for many node pairs therefore have high betweenness scores. Social network analysts have gone on to specify particular brokerage roles based on the actors' membership in groups (e.g., Gould and Fernandez 1989). For instance, a node occupies a "coordinator" role when it is interposed between nodes within its same group or organization. When the three nodes are members of different groups, the broker acts as a "liaison." Figure 6 depicts the brokerage roles operating when the broker and one actor are members of one group and the other actor is a member of a second group. Brokers (B) that mediate outflows from their own group are "representatives"; those that mediate inflows into their group are "gatekeepers."

[Figure 6 about here]

Identifying important brokers in a social network involves counting the number of triads in which the node is positioned as an intermediary. In the illicit arms trade, there are individuals 
and organizations that serve as brokers for particular arms transactions, and the IAT dataset records these actors and their roles when the information is available. Because this analysis is limited to state locales, however, to say that locale B served as a broker for transfers between A and $\mathrm{C}$ simply means that arms were shipped from A to B and arms - not necessarily the same ones-were shipped from B to C; but arms were not shipped from A to C. That is, locale B is a broker to the extent that B could possibly function as a conduit for the shipment of illegal weapons from A to C, based on observed arms trade patterns from 1990 to 2002.

I divide state locales into two groups, African and non-African countries, although potentially more interesting groupings would be possible for this sort of analysis (based on political and economic characteristics, and not simply geographic ones). If node $j$ is a broker for $i$ and $k$, then let $b_{j}(i k)=1$; otherwise $b_{j}(i k)=0$. Node $j$ 's brokerage score for the network is:

$$
B_{j}=\sum_{\forall i \neq j} \sum_{\forall k \neq j} b_{j}(i k)
$$

The score can be calculated conditional on the direction of the transaction flow and i's, $j$ 's, and k's group membership, so that brokerage scores correspond to $j$ 's role as a coordinator, representative, gatekeeper, etc..

Table 1 reports the scores for the top broker locales in Africa's illegal arms trade. It is no surprise that the leading gatekeepers are African countries: they are destinations for weapons shipped from non-African locales and departure points for arms shipped to other African locales. Angola and South Africa top the list, which conforms to their positions as the most central locales measured in terms closeness and betweenness. They, and especially South Africa, are also leading coordinators - destination and departure points for arms shipped among African 
countries. Moreover, South Africa is the most prominent broker locale in regard to the shipment of illegal arms out of Africa — to India, Pakistan, Sri Lanka, Colombia, and Ireland. However, other locales positioned as representative-type brokers are non-African countries (e.g., Belgium, Romania, Ukraine): they are destinations for arms shipped from other non-African countries and departure locales for shipments into Africa. Again, I want to emphasize that the data used here only allow me to identify as brokers those nodes interposed between supplier and recipient locales. Determining the extent to which these nodes serve as conduits for weapons cargo transferred between nonadjacent nodes requires shipment-level data that I am still in the process of collecting.

[Table 1 about here]

\section{CONCLUSION}

Network forms of organization are nonanarchical and nonhierarchical. Elsewhere I have argued that the conventional arms trade should be understood not as a market but as a network, one that shares some important properties with networked forms of organization studied by sociologists (Kinsella 2003). I have reiterated that argument here in regard to the illicit arms trade. Although the state-sanctioned arms trade does sometimes involve retransfers by recipients to third parties (authorized or unauthorized), it is the complex and convoluted nature of black market arms transfers that suits this realm of the arms trade especially well to investigation as a social network. Like any underground activity involving the exchange and transport of contraband (drugs, counterfeit currency, humans), the illicit arms trade operates within an informal organizational environment. The forces of supply and demand are mediated by the forces of 
trust, loyalty, and mutual commitment that govern the flow of information and material within a social network.

Since my dataset on the illicit arms trade are still at an early stage of development, the analysis in this paper employs only descriptive methods designed to explore the main structural features of social networks. The results are not definitive, but they are suggestive. Africa's black arms market is structured as a scale-free network, even when the network nodes are operationalized fairly crudely as state locales. The locales occupying central position in the network readily stand out. South Africa and Angola have especially high profiles; they are directly linked to many other locales and are positioned as potentially pivotal nodes for arms transfers following indirect routes. Among the countries where arms suppliers and transporters are located, former members of the Soviet bloc stand out, particularly Bulgaria, Romania, and Ukraine. One explanation for their prominence in Africa's illicit arms trade might be found in the availability of cold war surplus and a black market infrastructure nurtured originally by their communist economic systems. This, at least, is a reasonable working hypothesis for subsequent empirical research.

The utility of SNA methods (or any other quantitative methods) for illuminating the illicit arms trade obviously hinges on the quality of data that can be collected. Mapping the structure of the black market is hampered by the secrecy with which deals are concluded and the shadiness of the actors involved. What we do know about it is due mainly to the perseverance of enterprising activists and investigative reporters and, as with any data source, this information is subject to measurement error and selection bias. The analysis of network dynamics often requires fairly complete information about nodes and links, particularly if the aim is to model network 
vulnerabilities. If the lack of information makes it necessary to restrict analysis to sampled data, important elements of the network structure may be missed. However, this danger should be less pronounced when examining scale-free networks because even incomplete information is likely to identify the most prominent nodes. That is, the same feature that makes these networks robust in the face of random failure also makes them more visible in the face of systematic efforts to reveal them. If I am right that the illicit arms trade is a scale-free network, then the fact that some of it remains hidden from view need not prevent us from mapping its basic structure. 


\section{REFERENCES}

Barabási, Albert-László and Reka Albert. 1999. Emergence of Scaling in Random Networks. Science 286: 509-512.

Barabási, Albert-László and Eric Bonabeau. 2003. Scale-Free Networks. Scientific American 288(5): 60-69.

Bitzinger, Richard A. 1994. The Globalization of the Arms Industry: The Next Proliferation Challenge. International Security 19: 170-198.

Bradach, Jeffrey L. and Robert G. Eccles. 1989. Price, Authority, and Trust: From Ideal Types to Plural Forms. Annual Review of Sociology 15: 97-118.

Coase, R. H. 1937. The Nature of the Firm. Economica 4: 386-405.

Collier, Paul. 2000. Rebellion as a Quasi-Criminal Activity. Journal of Conflict Resolution 44: 839-853.

Cooper, Neil. 2002. Warlords and Logo Warriors: The Political Economy of Post-modern Conflict. In Arming the South: The Economics of Military Expenditure, Arms Production, and Arms Trade in Developing Countries, edited by Jurgen Brauer and J. Paul Dunne. New York: Palgrave.

Duffield, Mark. 2000. Globalization, Transborder Trade, and War Economies. In Greed and Grievance: Economic Agendas in Civil Wars, edited by Mats Berdal and David M. Malone. Boulder, Colo.: Lynne Rienner.

Eyre, Dana P. and Mark C. Suchman. 1996. Status, Norms, and the Proliferation of Conventional Weapons: An Institutional Theory Approach. In The Culture of National Security: Norms and Identity in World Politics, edited by Peter J. Katzenstein. New York: Columbia University Press. 
Finnemore, Martha. 1996. Norms, Culture, and World Politics: Insights from Sociology's Institutionalism. International Organization 50(2): 325-347.

Granovetter, Mark. 1985. Economic Action and Social Structure: The Problem of Embeddedness. American Journal of Sociology 91(3): 481-510.

Gould, Roger V. and Roberto M. Fernandez. 1989. "Structures of Mediation: A Formal Approach to Brokerage in Transaction Networks," Sociological Methodology 19: 89-126.

Kaldor, Mary. 1981. The Baroque Arsenal. New York: Hill and Wang.

Kaldor, Mary. 2001. New and Old Wars: Organized Violence in a Global Era. Stanford, Calif.: Stanford University Press.

Keohane, Robert O. 1984. After Hegemony: Cooperation and Discord in the World Political Economy. Princeton, N.J.: Princeton University Press.

Kinsella, David. 1994. Conflict in Context: Arms Transfers and Third World Rivalry During the Cold War. American Journal of Political Science 38 (3): 557-581.

Kinsella, David. 2000. Arms Production in the Third Tier: An Analysis of Opportunity and Willingness. International Interactions 26(3): 253-286.

Kinsella, David. 2003. Changing Structure of the Arms Trade: A Social Network Analysis. Paper presented at the annual meeting of the American Political Science Association, Philadelphia, 28-31 August. Available at http://web.pdx.edu/ kinsella/papers.html.

Kinsella, David and Jugdep S. Chima. 2001. Symbols of Statehood: Military Industrialization and Public Discourse in India. Review of International Studies 27(3): 353-373.

Klare, Michael. 1997. The Subterranean Arms Trade: Black-Market Sales, Covert Operations and Ethnic Warfare. In Cascade of Arms: Managing Conventional Weapons Proliferation, edited by Andrew J. Pierre. Washington, D.C.: Brookings Institution Press. 
Krause, Keith. 1992. Arms and the State: Patterns of Military Production and Trade.

Cambridge: Cambridge University Press.

Lindblom, Charles E. 1977. Politics and Markets: The World's Political Economic Systems. New York: Basic Books.

Lumpe, Lora, editor. 2000. Running Guns: The Global Black Market in Small Arms. London: Zed Books.

Marsh, Nicholas. 2002. Two Sides of the Same Coin? The Legal and Illegal Trade in Small Arms. Brown Journal of World Affairs 9: 217-228.

Mearsheimer, John J. 1994/95. The False Promise of International Institutions. International Security 19(3): 5-49.

Newman, M. E. J. 2003. The Structure and Function of Complex Networks. SIAM Review 45: $167-256$.

Morgenthau, Hans J. 1985. Politics Among Nations: The Struggle for Power and Peace, sixth edition, revised by Kenneth W. Thompson. New York: Knopf.

Norwegian Initiative on Small Arms Transfers (NISAT). 2004. NISAT Black Market Files, available at $<$ http: $/ /$ www.nisat.org/default.asp?page=/search.asp $>$.

Powell, Walter W. 1990. Neither Market nor Hierarchy: Network Forms of Organization. Research in Organizational Behavior 12: 295-336.

Scott, John. 2000. Social Network Analysis: A Handbook, second edition. Thousand Oaks, Calif.: Sage.

Shimbel, A. 1953. Structural Parameters of Communication Networks. Bulletin of Mathematical Biophysics 15: 501-507. 
Small Arms Survey. 2003. Small Arms Survey 2003: Development Denied. Oxford: Oxford University Press.

Suchman, Mark C. and Dana P. Eyre. 1992. Military Procurement as Rational Myth: Notes on the Social Construction of Weapons Proliferation. Sociological Forum 7(1): 137-161.

Wasserman, Stanley and Katherine Faust. 1994. Social Network Analysis: Methods and Applications. Cambridge: Cambridge University Press.

Wendt, Alexander. 1999. Social Theory of International Politics. Cambridge: Cambridge University Press.

Wendt, Alexander and Michael Barnett. 1993. Dependent State Formation and Third World Militarization. Review of International Studies 19: 321-347.

Williamson, Oliver E. 1981. The Economics of Organization: The Transaction Cost Approach. American Journal of Sociology 87(3): 548-577.

Wood, Brian and Johan Peleman. 1991. The Arms Fixers: Controlling the Brokers and Shipping Agents. Peace Research Institute of Oslo, Report 3/99.

Wrong, Dennis. 1961. The Oversocialized Conception of Man in Modern Sociology. American Sociological Review 26(2): 183-193. 


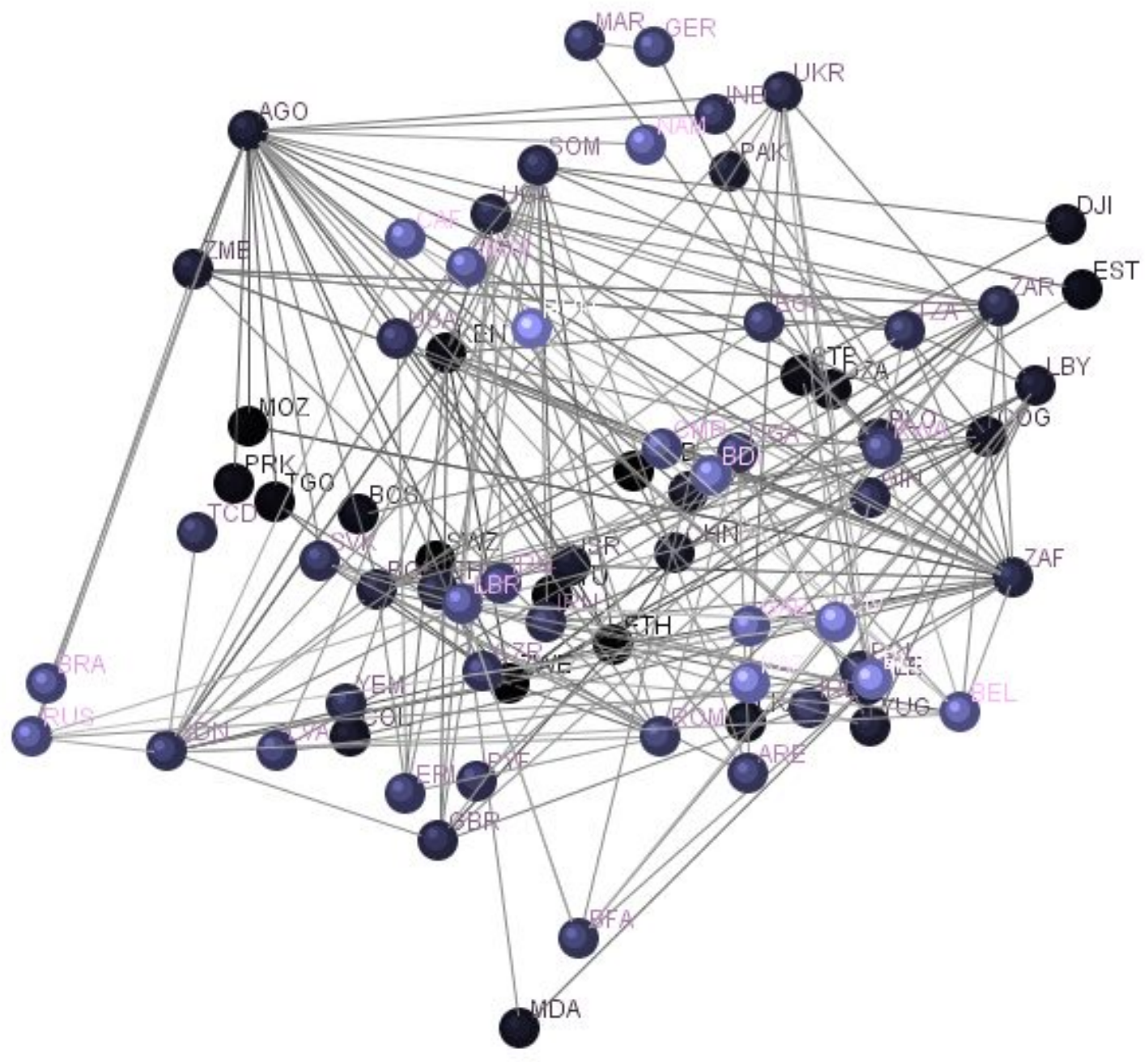

Figure 1: Locales in the Illicit Arms Trade in Africa 

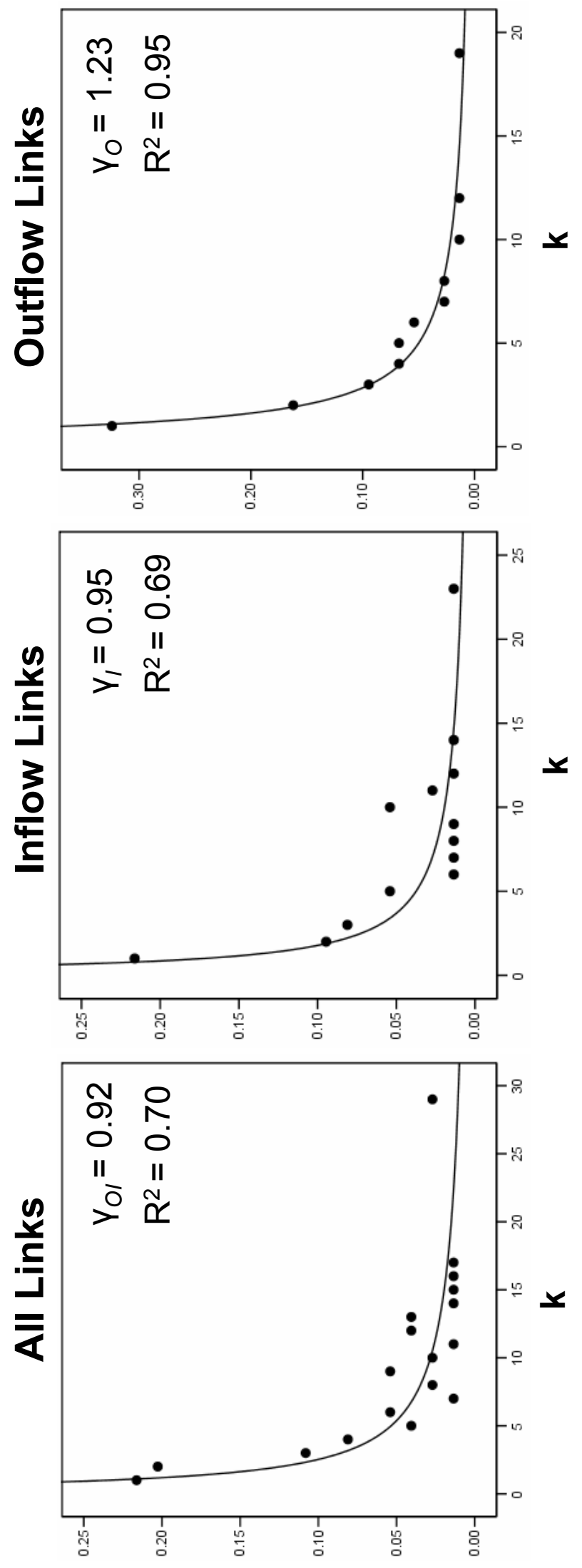

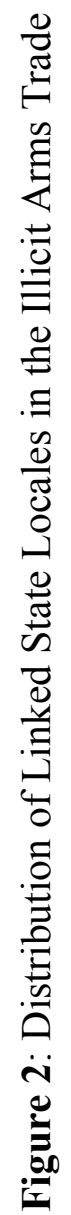

(y)d 


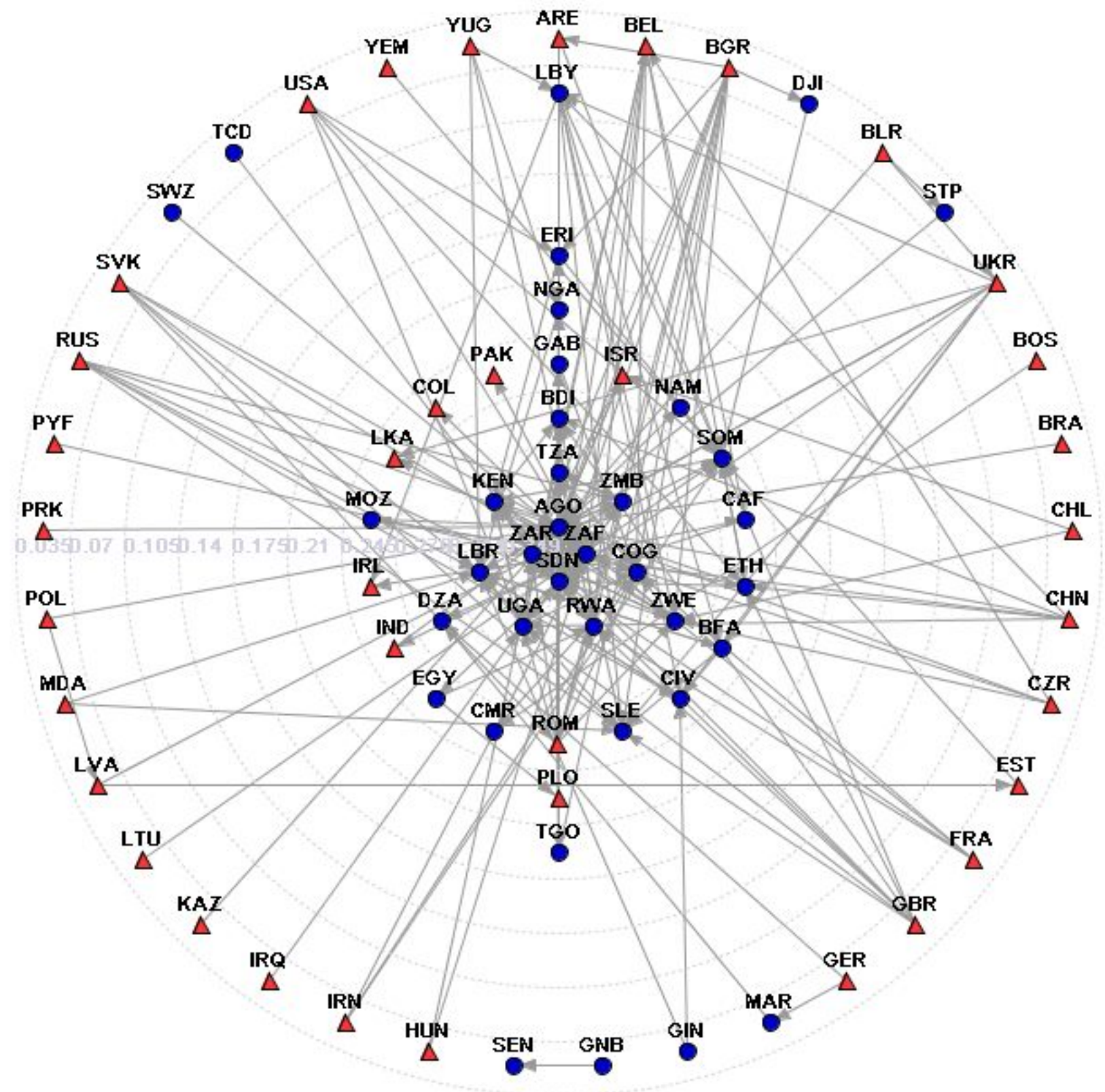

Figure 3: Inflow Centrality in Africa's Illicit Arms Trade 


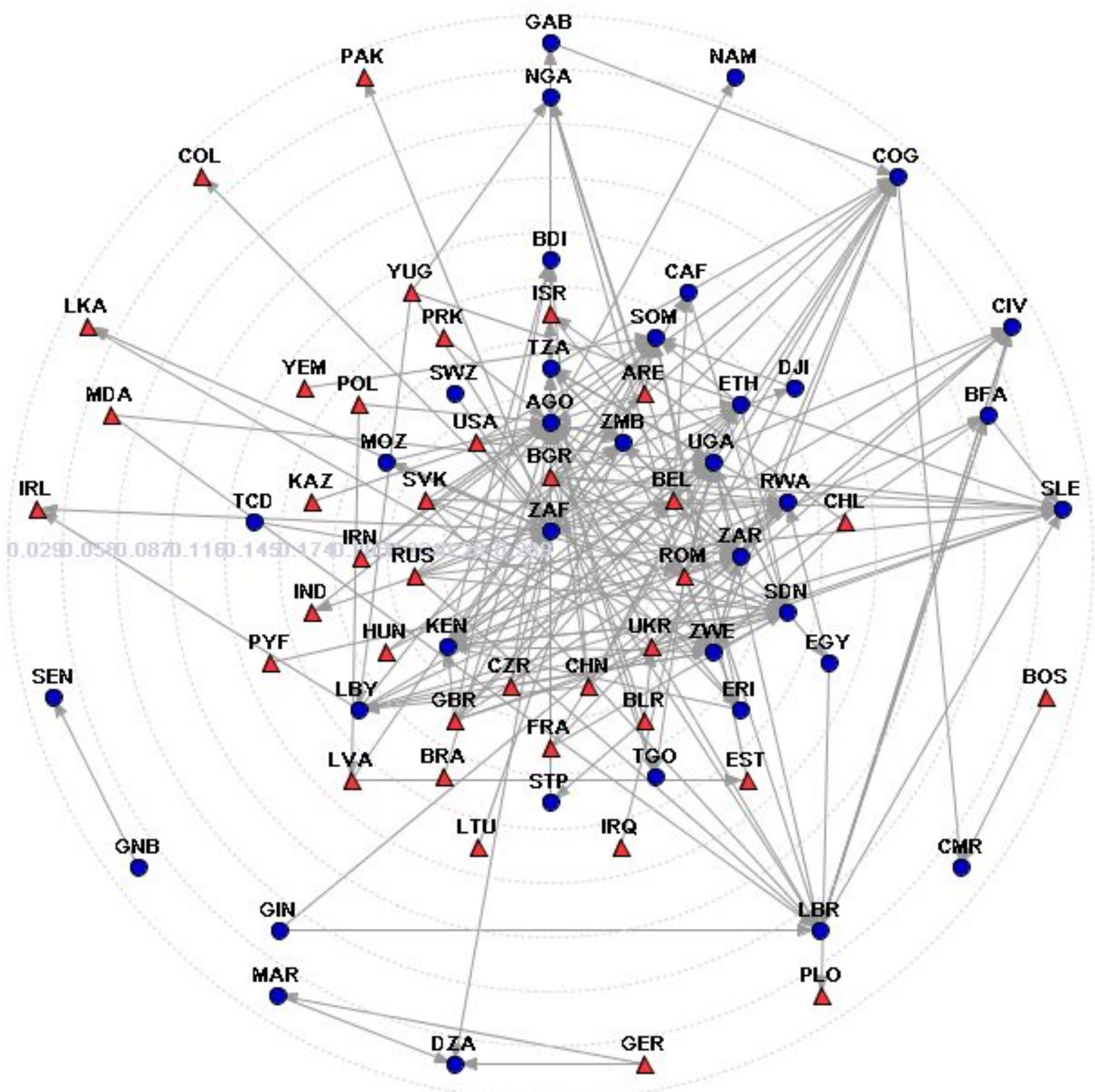

Figure 4: Outflow Centrality in Africa's Illicit Arms Trade 


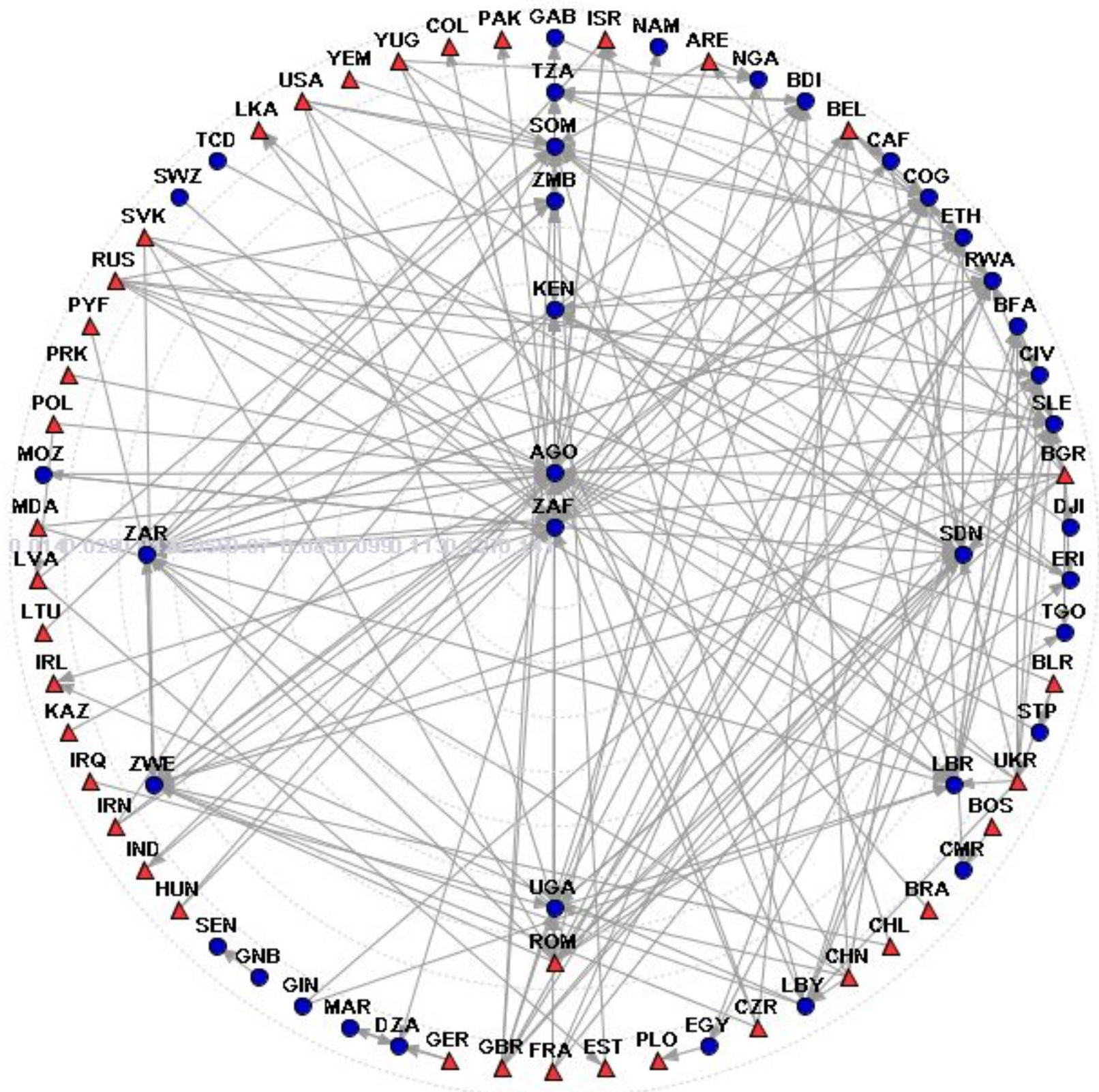

Figure 5: Betweenness Centrality in Africa's Illicit Arms Trade 


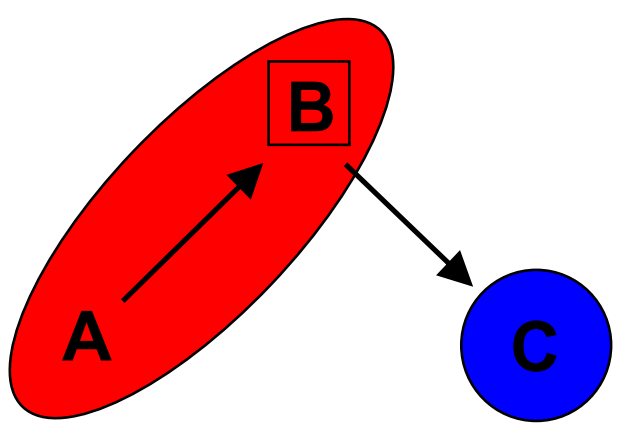

Representative

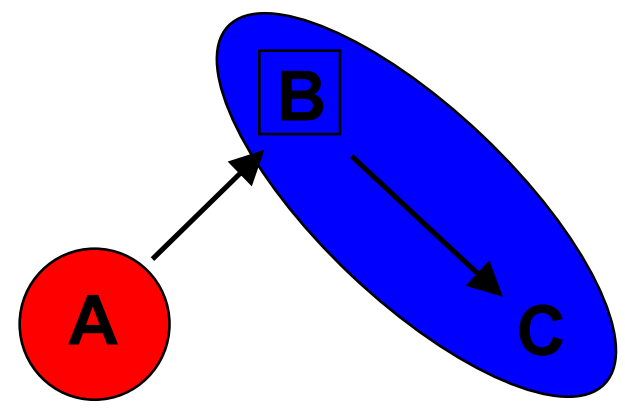

Gatekeeper

Figure 6: Brokerage Roles 
Table 1: Leading Broker Locales in the Africa's Illicit Arms Trade

\begin{tabular}{|c|c|c|c|c|}
\hline Broker Locale & Gatekeeper & Coordinator & Broker Locale & Representative \\
\hline Angola & 78 & 27 & South Africa & 25 \\
\hline South Africa & 60 & 55 & Belgium & 12 \\
\hline Uganda & 22 & 10 & Romania & 10 \\
\hline Sudan & 17 & 14 & Angola & 7 \\
\hline Dem. Rep. of Congo & 15 & 17 & Ukraine & 6 \\
\hline Libya & 11 & $0 *$ & Zambia & 4 \\
\hline Zimbabwe & 10 & 7 & Israel & 2 \\
\hline Rwanda & 8 & $4 *$ & United Arab Emirates & 2 \\
\hline Liberia & 7 & 10 & Egypt & 1 \\
\hline Somalia & 7 & $2 *$ & Latvia & 1 \\
\hline
\end{tabular}

* Not among the top ten coordinator locales. 